\title{
The ery-M2 Group of Chlamydomonas reinhardii: Cold-sensitive, Erythromycin-resistant Mutants Deficient in Chloroplast Ribosomes
}

\author{
By MAUREEN R. HANSON AND LAWRENCE BOGORAD \\ Department of Biology, Harvard University, Cambridge, Massachusetts 02138, U.S.A.
}

(Received 9 September 1977)

\begin{abstract}
Erythromycin-resistant mutants mapping to the Mendelian ery-M2 locus of Chlamydomonas reinhardii were cold-sensitive for growth at $15^{\circ} \mathrm{C}$. The phenotypes erythromycin-resistance and cold-sensitivity could not be separated in crosses.

Mutants at the ery-M2 locus were previously found to have chloroplast ribosomes with altered $\left[{ }^{14} \mathrm{C}\right]$ erythromycin binding capacity (Mets \& Bogorad, 1971). When grown at $25{ }^{\circ} \mathrm{C}$, haploid strains containing ery-M2 alleles alone or in combination with other ery loci had fewer chloroplast ribosomes than the wild type. A further reduction occurred when ery-M2 strains were shifted to $15^{\circ} \mathrm{C}$. Diploids containing both ery-M2 and its wild-type allele contained normal amounts of chloroplast ribosomes at 25 and $15{ }^{\circ} \mathrm{C}$, and were cold-resistant and antibiotic-sensitive.

The inability of chloroplast ribosome-deficient ery-M2 strains to grow at $15{ }^{\circ} \mathrm{C}$ in the presence of a reduced carbon source indicates that chloroplast protein synthesis is essential for cellular growth even when photosynthesis is not essential.
\end{abstract}

\section{INTRODUCTION}

Mutants with alterations in the level of chloroplast ribosomes can be used to evaluate the importance of these ribosomes to cellular activities. A number of Chlamydomonas mutants with reduced numbers of chloroplast ribosomes are known (Boynton, Gillham \& Chabot, 1974; Goodenough et al., 1971; Harris, Boynton \& Gillham, 1974). These chloroplast ribosome-deficient mutants were selected for a deficiency in photosynthesis expressed as slow growth in the absence of a reduced carbon source (acetate). A type of mutant which has been useful in studying bacterial ribosomes (Davies \& Nomura, 1972; Flaks et al., $1966)$ is the temperature-sensitive ribosome assembly-defective mutant.

Mets \& Bogorad (1972) had previously found that erythromycin-resistant ery-M2 Chlamydomonas reinhardii mutants had reduced amounts of chloroplast ribosomes when grown at the usual culture temperature of $25^{\circ} \mathrm{C}$. Chloroplast ribosomes from ery-M2 mutants have altered $\left[{ }^{14} \mathrm{C}\right]$ erythromycin binding (Mets \& Bogorad, 1971). There is evidence that a basic, low molecular weight protein is altered in the large chloroplast subunit of an ery-M2 mutant (Mets \& Bogorad, 1972).

Any alteration in a ribosomal protein has the potential of affecting ribosome assembly and/or stability. A number of bacterial ribosome mutants have multiple phenotypes, e.g. temperature-sensitivity and antibiotic-resistance (Nashimoto et al., 1971; Pardo \& Rosset, 1974; Feunteun et al., 1974). We therefore screened a collection of erythromycin-resistant mutants of $C$. reinhardii for temperature-sensitivity at 15 and $35^{\circ} \mathrm{C}$. Five mutants belonging to the ery-M2 group were cold-sensitive for growth at $15^{\circ} \mathrm{C}$. We now report an analysis of the cold-sensitive phenotype by determination of growth characteristics and ribosome content and by genetic studies. 


\section{METHODS}

Strains and genetic analysis. The erythromycin-resistant mutants of $C$. reinhardii used represented one uniparental (U) and three Mendelian (M) loci. Mutants ery-M1a, b, c and d, ery-U1a and ery-M2a, b, c and d were erythromycin-resistant strains described by Mets \& Bogorad (1971). Mutant ery-M2e, mating type $(+)$, originally ery $12(+)$, was obtained from N. W. Gillham and found to be linked to the ery-M2 mutants by Davidson (1976). Mutant ery-M3a was originally ery $2 \mathrm{y}$ from N. W. Gillham, and represents a third Mendelian locus unlinked to ery-M1 or ery-M2 (Davidson, 1976).

Standard techniques for crossing and tetrad analysis of $C$. reinhardii were used (Levine \& Ebersold, 1960). Vegetative diploids were isolated according to the method of Ebersold (1967) and Gillham (1963).

Growth tests. The minimal high salts (HS) medium used was similar to that of Sueoka (1960). Growth of strains at 15,25 and $35^{\circ} \mathrm{C}$ was compared on solid HS medium or HS medium supplemented with acetate (HSA) or with yeast extract, peptone and acetate (YPA HS). Media containing Tris buffer were not used because the $\mathrm{pH}$ of this buffer is strongly temperature-dependent.

Resistance to erythromycin (Sigma), cleocin (Upjohn, Kalamazoo, Michigan, U.S.A.) and lincomycin (Upjohn) was evaluated on solid HS media containing various concentrations of these filter-sterilized antibiotics.

Drop growth tests were carried out by placing strains in liquid HS medium for 2 to $6 \mathrm{~h}$ before adding drops to test plates. Relative growth was evaluated after 1 week at $35^{\circ} \mathrm{C}, 2$ weeks at $25^{\circ} \mathrm{C}$ and 3 weeks at $15^{\circ} \mathrm{C}$.

Minimum inhibitory concentration determinations for erythromycin were done as described by Davidson \& Bogorad (1977). Tubes were scored for growth after 2 weeks incubation at $25^{\circ} \mathrm{C}$.

Preparation and analysis of cellular fractions. Despite attempts by numerous laboratories, no satisfactory method for the isolation of chloroplasts from Chlamydomonas has yet been described. Therefore, no attempts were made to analyse chloroplast ribosomes prepared from isolated chloroplasts.

Strains were grown in liquid $\mathrm{HS}$ medium at 15 or $25^{\circ} \mathrm{C}$ under $5 \%(\mathrm{v} / \mathrm{v}) \mathrm{CO}_{2}$ and 4 to $8 \mathrm{klx}$ illumination. Cultures were harvested in a Sorvall G3 rotor, washed and resuspended to $2 \times 10^{8}$ to $5 \times 10^{8} \mathrm{cells}^{-1}$ in 25-25-25-5 buffer (25 mM- $\mathrm{MgCl}_{2}, 25 \mathrm{~mm}-\mathrm{KCl}, 25 \mathrm{~mm}$-Tris/HCl, $5 \mathrm{~mm}$-dithiothreitol, pH 7.5). Cells were broken by two passages through a Yeda press at $1500 \mathrm{lbf} \mathrm{in}^{-2}(9 \cdot 4 \mathrm{MPa})$. Small-scale preparations for analysis of rRNA by polyacrylamide gel electrophoresis were sometimes made by the sonicator-bath technique of Simon (1974). The homogenate was centrifuged at $17000 \mathrm{rev} . \mathrm{min}^{-1}$ for $20 \mathrm{~min}$ in a Sorvall SS34 rotor. The supernatant was centrifuged again at $17000 \mathrm{rev} . \mathrm{min}^{-1}$ for $20 \mathrm{~min}$. The pellets from both centrifugations were combined and resuspended in 25-25-25-5 buffer. The final supernatant (S17) and the combined pellets (P17) were stored in liquid nitrogen after adding RNAase-free sucrose to $5 \%(\mathrm{w} / \mathrm{v})$.

Ribosomal subunits in S17 and P17 fractions were analysed on exponential sucrose gradients at $4{ }^{\circ} \mathrm{C}$. Ribosomal RNAs were analysed by polyacrylamide gel electrophoresis as described by Hanson \& Bogorad $(1977 b)$.

Total RNA analysis. Phenol extracts of total cellular RNA were made according to the method of Cattolico \& Jones (1972). Gel electrophoresis of a sample containing 1 to $2 A_{260}$ units was done as described by Hanson \& Bogorad (1977 b). Before electrophoresis, 0.1 vol. 250-250-250-50 buffer ( $250 \mathrm{mM}-\mathrm{MgCl}_{2}, 250 \mathrm{mM}-\mathrm{KCl}$, $250 \mathrm{~mm}$-Tris/ $\mathrm{HCl}, 50 \mathrm{~mm}$-dithiothreitol, $\mathrm{pH} \mathrm{7.5)}$ was added to the sample. Relative amounts of different species of rRNA were calculated from absorbance scans of gels at $260 \mathrm{~nm}$. Relative peak areas were obtained by weighing pieces of Xerox copies of gel scans. The relative areas were converted to mol \% using the Chlamydomonas rRNA molecular weight values given by Cattolico, Senner \& Jones (1973).

\section{RESULTS}

Cold-sensitivity and erythromycin-resistance of haploid strains containing ery-M 2 alleles

Wild-type, as well as mutant strains ery-M1a, b, c, d, ery-M3a and ery-U1a grew well at 15 and $35^{\circ} \mathrm{C}$. However, the ery-M2 mutants did not grow at $15{ }^{\circ} \mathrm{C}$ on minimal medium nor on media supplemented with acetate, yeast extract and peptone (Table 1). The ery-M2 mutants apparently have a narrow optimum growth range; the mutants did not grow as well at 30 to $35^{\circ} \mathrm{C}$ as at $25{ }^{\circ} \mathrm{C}$.

The haploid double mutants ery-M2d ery-U1a and ery-M2d ery-M3a were also erythromycin-resistant and cold-sensitive on minimal and on supplemented media (Tables 1 and 2). Presence of both the ery-M2d and ery-U1a alleles resulted in a strain which grew slowly even at $25^{\circ} \mathrm{C}$ with no antibiotic (Table 2). The double mutant class ery-M1 ery-M2 was not tested because the combination of these two alleles is lethal (Mets \& Bogorad, 1971). 
Table 1. Growth of $C$. reinhardii strains at $15^{\circ} \mathrm{C}$ on solid media

\begin{tabular}{|c|c|c|c|}
\hline \multirow[b]{2}{*}{ Strain } & \multicolumn{3}{|c|}{ Relative growth* } \\
\hline & HS medium & $\begin{array}{l}\text { YPA HS } \\
\text { medium }\end{array}$ & $\begin{array}{l}\text { HS medium with } \\
100 \mu \mathrm{g} \\
\text { erythromycin ml } \mathrm{ml}^{-1}\end{array}$ \\
\hline Wild type & $++t+$ & $+t+t$ & 0 \\
\hline ery-M2a & 0 & 0 & 0 \\
\hline ery-M2b & 0 & 0 & 0 \\
\hline ery-M2c & 0 & 0 & 0 \\
\hline ery-M2d & 0 & 0 & 0 \\
\hline$e r y-\mathrm{M} 2 \mathrm{e}$ & 0 & 0 & 0 \\
\hline ery-U1a & ++++ & ++++ & ++++ \\
\hline ery-M2d ery-U1a & 0 & 0 & 0 \\
\hline ery-M3a & ++++ & $++t+$ & $+t+t$ \\
\hline ery-M2d ery-M3a & 0 & 0 & 0 \\
\hline$+/ e r y-\mathrm{M} 2 \mathrm{~b}$ & $+++t$ & ++++ & 0 \\
\hline$+/$ ery-M2d & $+t+t$ & $+++t$ & 0 \\
\hline ery-M1b $+/+e r y-\mathrm{M} 2 \mathrm{~d}$ & ++++ & $+t+t$ & $0+$ \\
\hline ery-M1b & $+++t$ & ++++ & ++++ \\
\hline$+/$ ery-M1b & ++++ & $+++t$ & + \\
\hline
\end{tabular}

$* 0$, No growth; $0+$, very slight growth;,,,+++++++++ , relative growth scores in increasing order, with ++++ being the amount of growth of wild type after 3 weeks at $15^{\circ} \mathrm{C}$ in the absence of antibiotics.

Table 2. Growth of $C$. reinhardii strains at $25^{\circ} \mathrm{C}$ on minimal medium containing various concentrations of erythromycin

\begin{tabular}{lccccc}
\multicolumn{5}{c}{ Strain } & \multicolumn{5}{c}{ Erythromycin concn $\left(\mu \mathrm{g} \mathrm{ml}^{-\mathbf{1}}\right)$} \\
\cline { 2 - 5 } & 30 & 50 & 100 & 200 & 500 \\
Wild type & $++++*$ & 0 & 0 & 0 & 0 \\
ery-M2d & ++++ & ++++ & ++++ & ++++ & ++ \\
$+/$ ery-M2d & ++++ & 0 & 0 & 0 & 0 \\
ery-U1a & ++++ & ++++ & ++++ & ++++ & ++++ \\
ery-M2d ery-Ula & ++ & ++ & +++ & +++ & ++ \\
ery-M1b & ++++ & ++++ & ++++ & ++++ & ++ \\
$\quad$ /ery-M1b & ++++ & ++++ & ++++ & + & 0 \\
ery-M1b+/tery-M2d & ++++ & ++++ & ++ & $0+$ & 0 \\
ery-M3a & ++++ & ++++ & ++++ & ++++ & ++++ \\
ery-M2d ery-M3a & ++++ & ++++ & ++++ & ++++ & ++
\end{tabular}

* Symbols for relative growth are as in Table 1, except that ++++ is the amount of growth of wild type after 2 weeks at $25^{\circ} \mathrm{C}$.

\section{Association of the ery ${ }^{r}$ and cld $^{s}$ phenotypes}

Erythromycin-resistance $\left(e r y^{r}\right)$ and cold-sensitivity $\left(c l d^{\mathrm{s}}\right)$ are very closely linked and appear to result from a single mutation. A cross between wild type and ery-M2d yielded over $95 \%$ germination of zygotes and over $97 \%$ progeny survival. Analysis of progeny from 63 zygotes did not reveal any cld $^{\mathrm{r}}$ ery $y^{\mathrm{r}}$ or cld $^{\mathrm{s}}$ er $y^{\mathrm{s}}$ recombinants. Crosses of mutants with $\arg -2$, arg-7, nic-15, nic-1, and arg-4 yielded no cld $^{\mathrm{r}}$ ery ${ }^{\mathrm{r}}$ or cld $^{\mathrm{s}}$ ery ${ }^{\mathrm{s}}$ recombinants in 150 tetrads examined.

To examine more progeny for recombination between $c l d^{8}$ and ery-M2, a form of random spore analysis (Davidson, 1976) was used. Mutant arg-2 was crossed with ery-M2d and zygotes were poured on to Petri dishes containing minimal medium. Mature zygotes were allowed to germinate into four or eight progeny on minimal medium. Progeny were then removed and plated at 25 and $15^{\circ} \mathrm{C}$ on minimal medium containing $100 \mu \mathrm{g}$ erythromycin $\mathrm{ml}^{-1}$. Cells of genotype $\arg -2$ cannot grow on minimal medium and cells of genotype 
Table 3. Growth of $C$. reinhardii strains at $25^{\circ} \mathrm{C}$ on minimal medium containing various concentrations of lincomycin and cleocin

\begin{tabular}{|c|c|c|c|c|c|}
\hline \multirow[b]{2}{*}{ Strain } & \multicolumn{2}{|c|}{ Lincomycin concn $\left(\mu \mathrm{g} \mathrm{ml}^{-1}\right)$} & \multicolumn{3}{|c|}{ Cleocin concn $\left(\mu \mathrm{g} \mathrm{ml}^{-1}\right)$} \\
\hline & 300 & 500 & 10 & 20 & 40 \\
\hline Wild type & $0 *$ & 0 & 0 & 0 & 0 \\
\hline$e r y-\mathrm{M} 2 \mathrm{~d}$ & $+++t$ & $t+t$ & $+t+t$ & ++ & + \\
\hline$+/ e r y-\mathrm{M} 2 \mathrm{~d}$ & 0 & 0 & 0 & 0 & 0 \\
\hline ery-Ula & + & 0 & 0 & 0 & 0 \\
\hline ery-M2d ery-Ula & ++ & ++ & ++ & ++ & ++ \\
\hline ery-M1b & $+t+t$ & $++t$ & 0 & 0 & 0 \\
\hline$+/$ ery-M1b & ++++ & +++ & 0 & 0 & 0 \\
\hline ery-M1b+/+ery-M2d & ++ & $+t$ & 0 & 0 & 0 \\
\hline ery-M3a & 0 & 0 & 0 & 0 & 0 \\
\hline ery-M2d ery-M3a & +++ & $++t+$ & +++ & +++ & +++ \\
\hline
\end{tabular}

* Symbols for relative growth are as in Table 2.

cld ery $^{\mathrm{r}}$ cannot grow at $15^{\circ} \mathrm{C}$. Only $c l d^{\mathrm{r}}$ ery $y^{\mathrm{r}}$ recombinants could grow on $100 \mu \mathrm{g}$ erythromycin $\mathrm{ml}^{-1}$ at $15^{\circ} \mathrm{C}$.

Growth was apparent on control plates which contained arginine and no erythromycin at $15{ }^{\circ} \mathrm{C}$, or contained erythromycin at $25^{\circ} \mathrm{C}$. However, no growth, and thus no $c l d^{\mathrm{r}}$ ery $\mathrm{y}^{\mathrm{r}}$ recombinants, were detected among approximately 10000 progeny tested. This result is strong evidence that the same mutation is conferring cold-sensitivity and erythromycinresistance. Another reason that the ery-M2 mutants are not likely to be double mutants is that ethyl methanesulphonate was used during their isolation (Mets \& Bogorad, 1971). Ethyl methanesulphonate, unlike nitrosoguanidine, does not induce closely linked mutations at high frequency (Guerola, Ingraham \& Cerda-Olmeda, 1971; Guerola \& Cerda-Olmeda, 1975).

\section{Reversion/suppression frequency}

Revertants or suppressed clones did not arise from ery-M2 mutants at a high frequency. Dilutions of ery-M2 strains grown at $25^{\circ} \mathrm{C}$ in HS medium were plated on HS or YPA HS media at $15^{\circ} \mathrm{C}$ and examined after 3 and 5 weeks. In several separate experiments, over $1 \times 10^{8}$ total cells were examined and only one cold-resistant colony was detected. Cells derived from this colony were as sensitive to erythromycin as the wild type and contained the normal amount of chloroplast ribosomes.

\section{Complementation analysis at the ery-M2 locus}

The characters antibiotic-resistance and cold-sensitivity conferred by the mutant ery-M2 allele are recessive. Heterozygous diploids (+/ery-M2) grew well at $15^{\circ} \mathrm{C}$ (Table 1$)$ and were inhibited by low concentrations of erythromycin (Table 2). The ery-M2 mutants are cross-resistant to lincomycin and cleocin, but +/ery-M2 diploids appear completely sensitive to these antibiotics on solid media (Table 3).

Minimum inhibitory concentration determinations in liquid culture on wild type, ery-M2d and + /ery-M2d revealed that the heterozygous diploid is slightly more resistant to erythromycin than the wild type (Table 4). However, the +/ery-M2 diploid is much less resistant than the +/ery-M1 diploids (Table 4 and Hanson \& Bogorad, 1977a).

\section{Ribosomal RNA present in cellular fractions of haploid strains}

Ribosomal RNAs from cold-sensitive Chlamydomonas mutants were examined because bacterial mutants with this phenotype are known to be ribosome assembly-defective and to contain increased amounts of precursor forms of rRNAs (Nashimoto et al., 1971; Feunteun et al., 1974). 
Table 4. Minimum inhibitory concentrations (m.i.c.) of erythromycin for C. reinhardii strains

M.i.c. in liquid

medium

( $\mu$ g erythromycin

Strain

Wild type

ery-M2d

$+/ e r y-\mathrm{M} 2 \mathrm{~d}$

ery-M1b

$+/ e r y-\mathrm{M} 1 \mathrm{~b}$ $\mathrm{ml}^{-1}$ )

10
250
20
$>\quad 200$
$>50$

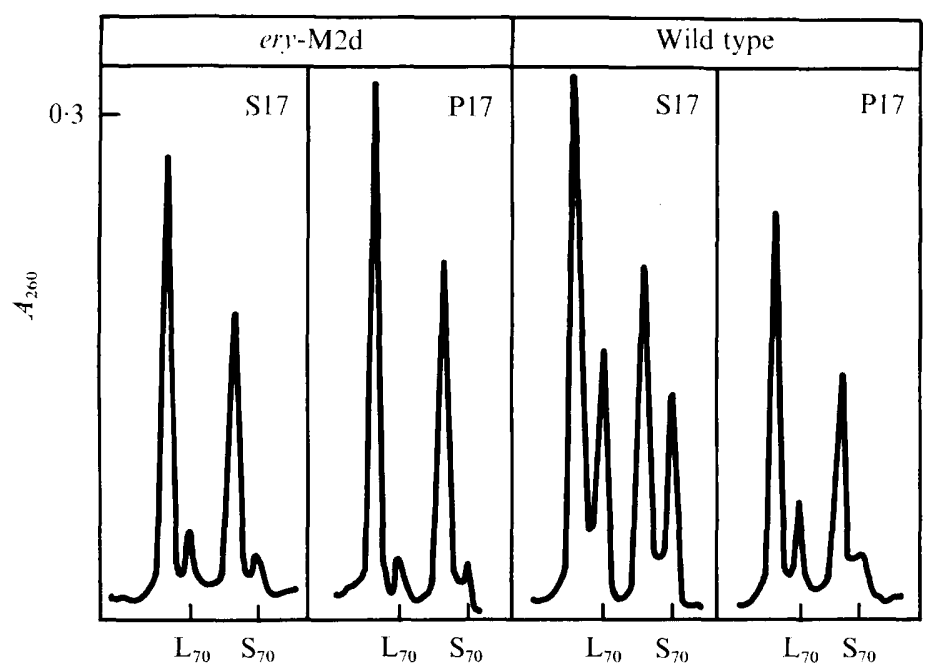

Fig. 1. Gel electrophoretic analysis of rRNA in S17 and P17 fractions from wild type and ery-M2d grown at $25^{\circ} \mathrm{C}$. $\mathrm{L}_{70}$, rRNA from large subunit of $70 \mathrm{~S}$ chloroplast ribosome; $\mathrm{S}_{70}$, rRNA from small subunit of $70 \mathrm{~S}$ chloroplast ribosome. The other two peaks represent the rRNA from the large and small subunits of the cytoplasmic (80S) ribosomes.

Precursor forms of chloroplast rRNAs were not detected in haploid strains containing ery-M2 alleles nor in wild type at 25 and $15^{\circ} \mathrm{C}$. However, quantitative alterations in chloroplast rRNAs were detected in ery-M2 strains.

Ribosomal RNA content could be used as a measure of ribosome content because no free rRNA could be detected in homogenates. Also, because the absolute amount of rRNA from cytoplasmic (80S) ribosomes per cell did not vary in different strains, rRNA from 80S ribosomes could be used as an internal standard for comparison of amounts of chloroplast rRNA.

The supernatant (S17) fractions from cells of wild type and ery-M1 mutants contained chloroplast rRNA as 35 to $40 \mathrm{~mol} \%$ of the total rRNA. The $\mathrm{S} 17$ fractions from ery-M2d cells grown on either minimal or acetate-supplemented medium contained only 13 to $18 \%$ chloroplast rRNA (Fig. 1). Unlike the Chlamydomonas mutant strain studied by Goodenough et al. (1971), the presence of acetate in the medium had no effect on the chloroplast ribosome content of ery-M2 mutants.

Because a mutant lacking chloroplast rRNA (ribosomes) in the supernatant fraction could possibly have a defect in the release of chloroplast ribosomes from membranes, the membrane (P17) fractions of mutants were also examined for rRNA content. However, the P17 fractions of ery-M2 mutants were not enriched in chloroplast rRNA in comparison with those of the wild type after growth at $25^{\circ} \mathrm{C}$ (Fig. 1) or after incubation at $15^{\circ} \mathrm{C}$.

The rRNA contents of $\mathrm{S} 17$ fractions of wild type, erythromycin-resistant mutants and 

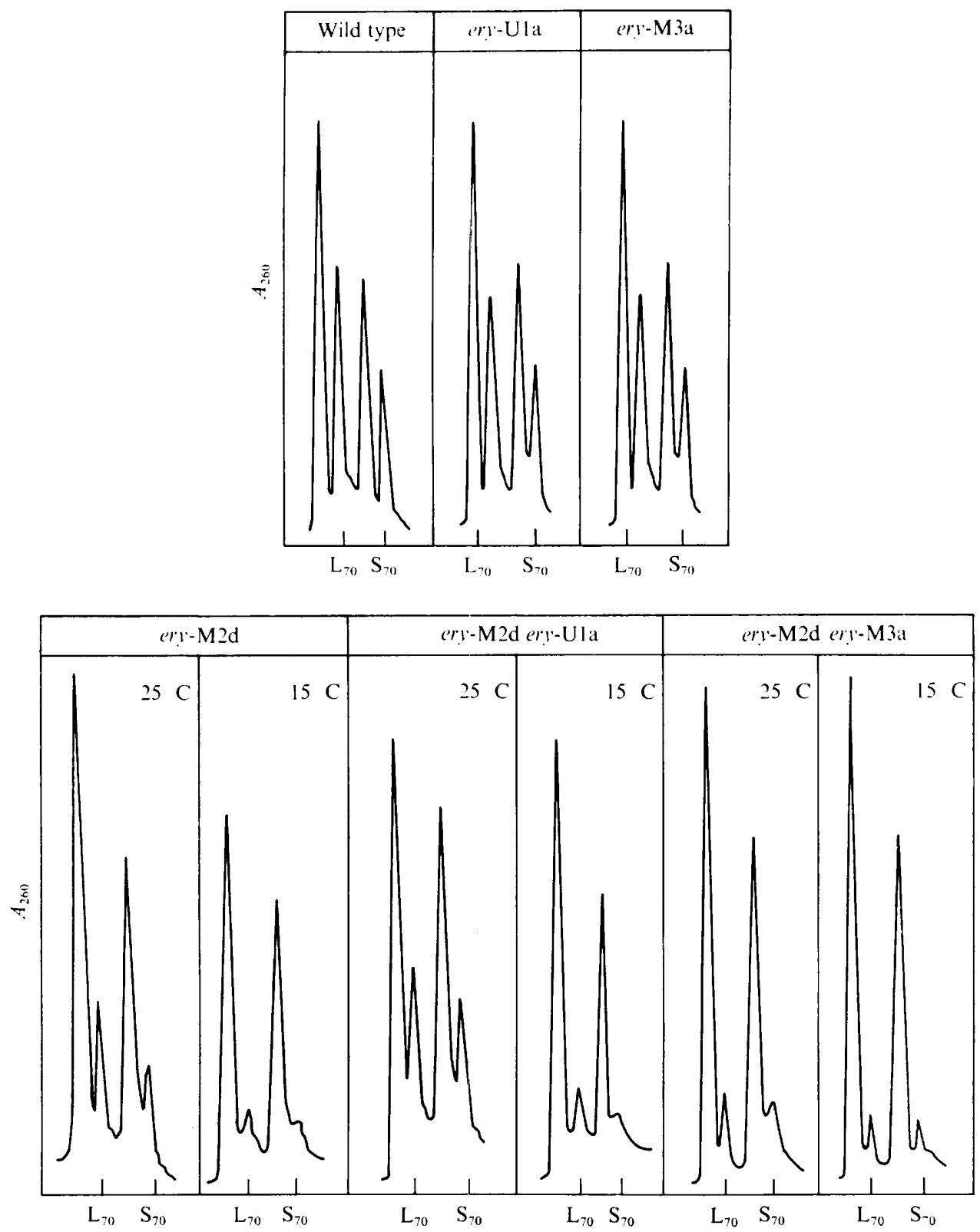

Fig. 2. Gel electrophoretic analysis of rRNA in S17 fractions from wild type, ery-M3a and ery-U1a grown at $25^{\circ} \mathrm{C}$, and from ery-M2d, ery-M2d ery-U1a and ery-M2d ery-M3a grown at $25^{\circ} \mathrm{C}$ and after $24 \mathrm{~h}$ incubation at $15^{\circ} \mathrm{C}$. Abbreviations as in Fig. 1.

double mutants after growth at $25^{\circ} \mathrm{C}$ and after $24 \mathrm{~h}$ at $15{ }^{\circ} \mathrm{C}$ are shown in Fig. 2. The rRNA content of wild-type cells is identical after growth at 25 or $15^{\circ} \mathrm{C}$. All of the strains carrying ery-M2d have reduced amounts of chloroplast rRNA at $25^{\circ} \mathrm{C}$ compared with wild type at $25^{\circ} \mathrm{C}$, and further reduction occurs at $15^{\circ} \mathrm{C}$. The double mutant ery-M2d ery-M3a has less chloroplast rRNA at $25^{\circ} \mathrm{C}$ than any of the ery-M2 mutants. 


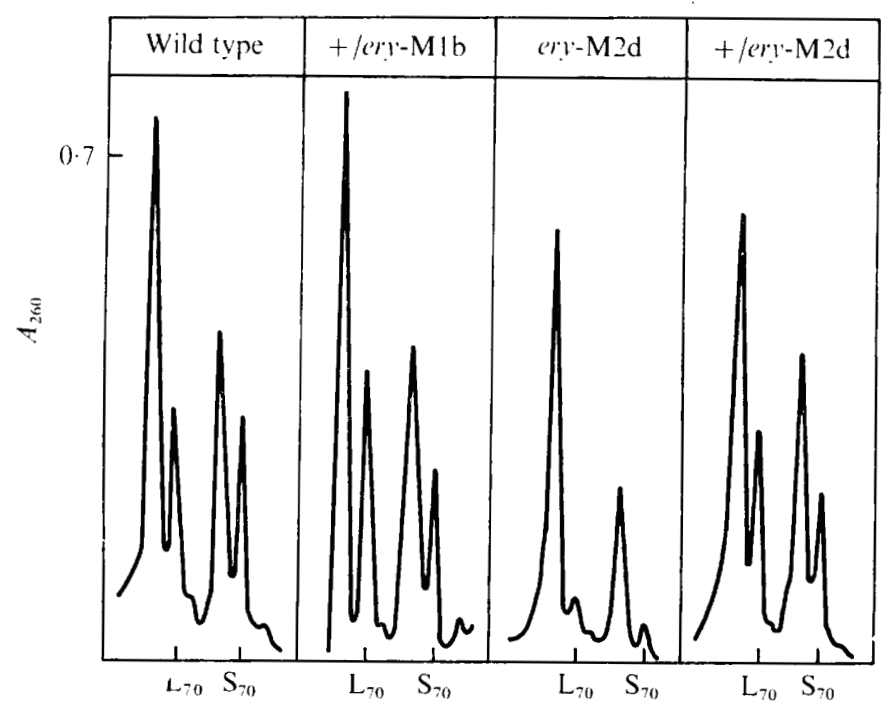

Fig. 3. Gel electrophoretic analysis of total cell RNA phenol extracts from wild type, ery-M2d and the heterozygous diploids +/ery-M1b and +/ery-M2d grown at $25^{\circ} \mathrm{C}$. Abbreviations as in Fig. 1.

\section{Chloroplast ribosomal RNA content of heterozygous diploids}

Total cell RNA from wild type, ery-M2 mutants, + /ery-M1 diploids and + /ery-M2 diploids was analysed by gel electrophoresis. Preparations from all these strains, except for the haploid ery-M2 mutants, had 35 to $40 \mathrm{~mol} \%$ chloroplast rRNA. The ery-M2 mutants again had only 13 to $18 \%$ chloroplast rRNA (Fig. 3). Thus, cold-sensitivity (Table 1), antibiotic-resistance (Table 2) and reduction in chloroplast RNA is recessive in + /ery-M2 diploids. This association of cold-resistance with normal amounts of chloroplast rRNA supports the hypothesis that the cld $^{\mathrm{s}}$ phenotype results from the absence of sufficient numbers of chloroplast ribosomes for cell survival and multiplication at $15^{\circ} \mathrm{C}$.

\section{Ratio of small to large subunits of chloroplast ribosomes in ery-M2 mutants}

Gel electrophoretic analyses of rRNA shown in Figs 1 to 3 indicate that the small and large subunit of the chloroplast ribosome are present in approximately equimolar amounts in the ery-M2 mutants. Although it is the large subunit which appears to have an altered ribosomal protein in the ery-M2 mutants (Mets \& Bogorad, 1972), both the large and small subunits are considerably reduced in these mutants.

To determine whether small differences exist in the amounts of small and large subunits of chloroplast ribosomes in the ery-M2 mutants, we employed sucrose gradients with salt conditions adjusted so that most chloroplast ribosomes remained associated as $70 \mathrm{~S}$ monomers. Under these conditions, a small difference in the ratio of small to large subunits would be detected more easily.

The sucrose gradient profiles of ribosomes of $\mathrm{S} 17$ fractions from wild type and two ery-M2 mutants grown at $25{ }^{\circ} \mathrm{C}$ (Fig. 4) revealed that the ratio of small to large subunits is slightly greater than 1 in the mutants. All five ery-M2 mutants had similar gradient profiles. This small difference in subunit ratio in the mutants was not detected by Mets \& Bogorad (1972) because the low-magnesium sucrose gradients they employed resulted in nearly complete dissociation of the chloroplast ribosomes into subunits.

After $12 \mathrm{~h}$ at the restrictive temperature of $15^{\circ} \mathrm{C}$, a further reduction in the large subunit of the chloroplast ribosome had occurred in the ery-M2 mutants (Fig. 5). The ribosome content of the membrane (P17) fraction was similar at both temperatures (Fig. 5). Evidently, 


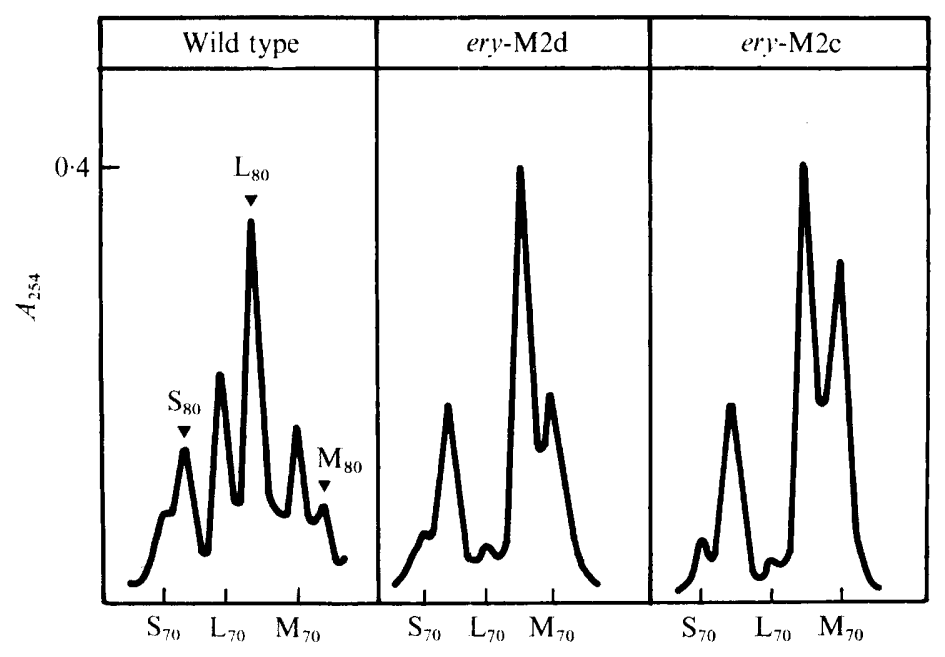

Fig. 4. Sucrose gradient analysis of $\mathrm{S} 17$ fractions from wild type, ery-M2d and ery-M2c grown at $25^{\circ} \mathrm{C}$. Gradients contained $25-500-50$ buffer $\left(25 \mathrm{~mm}-\mathrm{MgCl}_{2}, 500 \mathrm{mM}-\mathrm{KCl}, 50 \mathrm{~mm}-\mathrm{Tris} / \mathrm{HCl}, \mathrm{pH}\right.$ $7 \cdot 5$ ). Gradient profiles of ery-M2a, ery-M2b and ery-M2e were similar to those of the ery-M2 mutants shown. $S_{70}$, Small subunit of the $70 S$ chloroplast ribosome; $\mathbf{L}_{70}$, large subunit of the $70 \mathrm{~S}$ ribosome; $\mathrm{M}_{70}$, chloroplast ribosome monomer; $\mathrm{S}_{80}$, small subunit of the $80 \mathrm{~S}$ ribosome; $\mathrm{L}_{80}$, large subunit of the $80 \mathrm{~S}$ ribosome; $\mathrm{M}_{80}$, monomer of the $80 \mathrm{~S}$ ribosome.

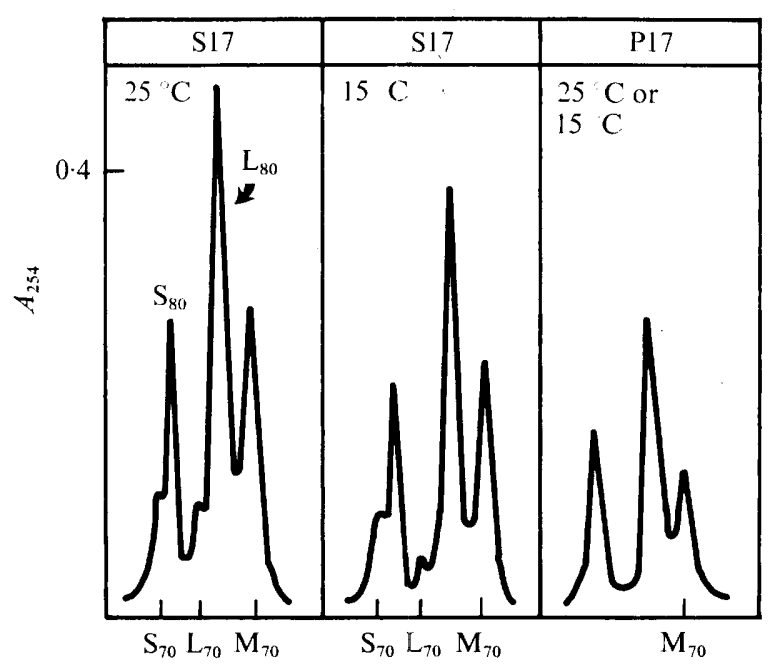

Fig. 5. Sucrose gradient analysis of S17 and P17 fractions from ery-M2d grown at $25^{\circ} \mathrm{C}$ and from ery-M2d after $12 \mathrm{~h}$ at $15^{\circ} \mathrm{C}$. The S17 and P17 fractions were dissolved in 25-25-25-5 buffer and run on gradients containing 25-500-50 buffer. Abbreviations as in Fig. 4.

there is a high degree of, but not a perfect, co-ordination of the amount of the chloroplast subunits in the ery-M2 mutants. Whether or not this co-ordinate reduction is a general feature of chloroplast ribosome-deficient mutants having alterations in the large subunit remains an open question until such mutants at other genetic loci have been isolated and characterized. Although no mutants have been described which are specifically deficient in the large subunit of the chloroplast ribosome, Harris et al. (1974) have described mutants specifically deficient in the small subunit. 
Table 5. Doubling times of phototrophically grown C. reinhardii mutants having reduced amounts of chloroplast ribosomes

\begin{tabular}{|c|c|c|c|}
\hline Genotype & $\begin{array}{l}\text { Doubling } \\
\text { time } \\
\text { (h) }\end{array}$ & $\begin{array}{l}\% \text { of normal } \\
\text { amount of } \\
\text { chloroplast } \\
\text { monomers* }\end{array}$ & Reference \\
\hline Wild type & $12 \cdot 8$ & 100 & Boynton et al. (1974) \\
\hline$a c-20$ & $18 \cdot 9$ & 32 & Boynton et al. (1974) \\
\hline$c r-1$ & $21 \cdot 1$ & 42 & Boynton et al. (1974) \\
\hline$a c-20, c r-1$ & $19 \cdot 9$ & 24 & Boynton et al. (1974) \\
\hline Wild type & $8 \cdot 5$ & 100 & This paper \\
\hline ery-M2d & 22 & $30-45$ & This paper \\
\hline
\end{tabular}

* The total amount of chloroplast monomer ribosomes which would be present if all subunits were associated was calculated from areas under chloroplast monomer and subunit peaks in absorbance scans of sucrose gradients.

\section{Effect of reduced chloroplast ribosome content on growth rate}

Although some degree of chloroplast protein synthesis appears necessary for vegetative growth even when a reduced carbon source is available, Chlamydomonas cells can continue to grow when chloroplast protein synthesis is much reduced. In the absence of an exogenously supplied carbon source, slow growth can be maintained even in mutants which have abnormally few chloroplast ribosomes. The ery-M2 mutants, as well as ac-20, $c r-1, c r-2$ $c r-3$ and $c r-4$, can all grow phototrophically, although with a lower doubling time than wild type has under the same conditions (Table 5).

\section{DISCUSSION}

The genetic data presented above indicate that the traits erythromycin-resistance and cold-sensitivity in ery-M2 mutants of Chlamydomonas are the consequence of a single nuclear gene mutation which affects chloroplast ribosomes. Furthermore, the cold-sensitivity for growth appears to result from a deficiency of chloroplast ribosomes at the restrictive temperature.

The reduced ribosome content of ery-M2 mutants at 25 and $15^{\circ} \mathrm{C}$ could be explained if a mutant form of a ribosomal protein has decreased affinity for assembling ribosomes. Mets \& Bogorad (1972) presented evidence for an altered chloroplast ribosomal protein in ery-M2 mutants.

Decreased affinity of a ribosomal protein for an assembling ribosome could also explain the phenotype of the +/ery-M2 diploids, which are much more sensitive to erythromycin than the + /ery-M1 diploids. The +/ery-M1 diploids are quite resistant to erythromycin although they contain only 30 to $40 \%$ erythromycin-resistant chloroplast ribosomes (Hanson \& Bogorad, 1977). Therefore, the high degree of erythromycin-sensitivity of + /ery-M2 diploids indicates that few erythromycin-resistant ribosomes are present in these diploids. This situation would result if, in a diploid containing ery-M2 and its wild-type allele, the mutant gene product is less likely to be incorporated into an assembling ribosome.

The cold-sensitivity for growth of the ery-M2 mutants implies that chloroplast protein synthesis is not dispensable when cells are given a reduced carbon source, contrary to the suggestion of Boynton et al. (1974) and Harris et al. (1974). All haploid strains carrying mutations at the ery-M2 locus, alone or in combination with ery-M3a and ery-U1a, were cold-sensitive even when provided with a reduced carbon source. Previous evidence for the importance of chloroplast protein synthesis in $C$. reinhardii was that ery-M1 ery-M2 recombinants are not viable - this combination of mutations in two genes affecting the chloroplast ribosome is lethal (Mets \& Bogorad, 1971). 
Chloroplast protein synthesis is apparently essential for growth of Chlamydomonas even under heterotrophic conditions, when photosynthesis is not essential for growth. This fact emphasizes the interdependence of genetic information storage and processing in the chloroplast and nuclear-cytoplasmic systems. It will be valuable to identify the products of chloroplast protein synthesis necessary for heterotrophic cellular growth.

This work was supported by the Maria Moors Cabot Foundation of Harvard University and by grant GM 20470 to L. Bogorad from the National Institutes of Health. We wish to thank J. N. Davidson and L. Mets for providing Chlamydomonas strains and helpful discussions.

\section{REFERENCES}

Boynton, J. E., Gillham, N. W. \& Chabot, J. F. (1974). Chloroplast ribosome deficient mutants in the green alga Chlamydomonas reinhardi and the question of chloroplast ribosome function. Journal of Cell Science 10, 267-305.

Cattolico, R. A. \& Jones, R. F. (1972). Isolation of stable ribosomal RNA from whole cells of Chlamydomonas reinhardii. Biochimica et biophysica acta 269, 259-264.

Cattolico, R. A., Senner, J. W. \& Jones, R. F. (1973). Changes in cytoplasmic and chloroplast ribosomal RNA during the cell cycle of Chlamydomonas reinhardi. Archives of Biochemistry and and Biophysics 156, 58-65.

DAVIDSON, J. N. (1976). Genes affecting erythromycin resistance in ery-M1 mutants of Chlamydomonas reinhardi. Ph.D. thesis, Harvard University, U.S.A.

Davidson, J. N. \& Bogorad, L. (1977). Suppression of erythromycin resistance in ery-M1 mutants of Chlamydomonas reinhardi. Molecular and General Genetics (in the Press).

Davies, J. \& Nomura, M. (1972). The genetics of bacterial ribosomes. Annual Review of Genetics 6, 203-234.

EBERSOLD, W. T. (1967). Chlamydomonas reinhardi: heterozygous diploid strains. Science 157, 447449.

Feunteun, J., Monier, R., Vola, C. \& Rosset, R. (1974). Ribosomal assembly and defective mutants of Escherichia coli. Nucleic Acids Research 1, 141-148.

Flaks, J. G., Leboy, P. S., Birge, E. H. \& Kurland, C. G. (1966). Mutation and genetics concerned with the ribosome. Cold Spring Harbor Symposia on Quantitative Biology 31, 623-631.

GillhaM, N. W. (1963). Transmission and segregation of a non-chromosomal factor controlling streptomycin resistance in diploid Chlamydomonas. Nature, London 200, 294.

Goodenough, U. W., Togasaki, R. K., Paszewski, A. \& LeVine, R. P. (1971). Inhibition of chloroplast ribosome formation by gene mutation in Chlamydomonas reinhardi. In Autonomy and Biogenesis of Mitochondria and Chloroplasts, pp. 224 234. Edited by N. K. Boardman, A. W. Linnane and R. M. Smillie. Amsterdam: North-Holland.

Guerola, N. \& Cerda-Olmeda, E. (1975). Distribution of mutations induced by ethyl meth- anesulfonate and ultraviolet radiation in the Escherichia coli chromosome. Mutation Research 29, 145-147.

Guerola, N., Ingraham, J. L. \& Cerda-Olmeda, E. (1971). Induction of closely linked multiple mutations by nitrosoguanidine. Nature New Biology 230. 122-125.

Hanson, M. R. \& Bogorad, L. (1977a). Complementation analysis at the ery-M1 locus in Chlamydomonas reinhardi. Molecular and General Genetics 153, 271-277.

Hanson, M. R. \& Bogorad, L. (1977 b). Effects of erythromycin on membrane-bound chloroplast ribosomes from wild-type Chlamydomonas reinhardi and erythromycin-resistant mutants. Biochimica et biophysica acta 479, 279-289.

Harris, E. H., Boynton, J. E. \& Gillham, N. W. (1974). Chloroplast ribosome biogenesis in Chlamydomonas. Selection and characterization of mutants blocked in ribosome formation. Journal of Cell Biology 63, 160-179.

LeVine, R. P. \& Ebersold, W. T. (1960). The genetics and cytology of Chlamydomonas. Annual Review of Microbiology 14, 197-216.

Mets, L. J. \& Bogorad, L. (1971). Mendelian and uniparental alterations in erythromycin binding by plastid ribosomes. Science 174, 707-709.

MeTs, L. J. \& Bogorad, L. (1972). Altered chloroplast ribosomal proteins associated with erythromycin-resistant mutants in two genetic systems of Chlamydomonas reinhardi. Proceedings of the National Academy of Sciences of the United States of America 69, 3779-3783.

Nashimoto, H., Held, W., Kaltschmidt, E. \& Nomura, M. (1971). Structure and function of bacterial ribosomes. XII. Accumulation of 21S particles by some cold-sensitive mutants of Escherichia coli. Journal of Molecular Biology 62, 121-138.

Pardo, D. \& Rosset, R. (1974). Genetic studies of erythromycin resistant mutants of Escherichia coli. Molecular and General Genetics 135, 257-268.

Simon, R. D. (1974). The use of an ultrasonic bath to disrupt cells suspended in volumes of less than 100 microliters. Analytical Biochemistry 60, 51-58.

SueoKA, N. (1960). Mitotic replication of DNA in Chlamydomonas reinhardi. Proceedings of the National Academy of Sciences of the United States of America 46, 83-91. 